\title{
CONSIDERATION OF REPUTATION PREDICTION OF LADYGAGA USING THE MATHEMATICAL MODEL OF HIT PHENOMENA
}

\author{
KawahataYasuko ${ }^{1}$, Genda Etsuo $^{1}$, and Ishii Akira $^{2}$ \\ ${ }^{1}$ Department of Contents and Creative Design, Graduate School of Design, Kyushu \\ University Hakozaki, Higashi-ku, Fukuoka,Japan \\ ${ }^{2}$ Department of Applied Mathematics and Physics Tottori University \\ Koyama, Tottori, Japan
}

\begin{abstract}
A mathematical model for the hit phenomenon in entertainment within a society is presented as a stochastic process of interactions of human dynamics. The calculations for the Japanese motion picture market based on to the mathematical model agree very well with the actual residue distribution in time. LADYGAGA are also analyzed using the data of SNS as well.
\end{abstract}

\section{KEYWORDS}

Hitphenomena,Advertisement,Music concert,WOM, Twitter, LADYGAGA

\section{INTRODUCTION}

The popularity of entertainment event by using the change of the day for each of the number of SNS posting, "the mathematical theory for hit phenomena" has been presented [1-3]. Nowadays, such estimation can be done by using the number of posted comments in the social network services (SNS) like weblogs, Facebook, Twitter, BBS (bulletin board system), and other similar services around the world, interactions between accounts can be stocked as digital data. We can assume that communication in the SNS society is very similar to that in real society. Thus, we can use the huge stock of digital data of human communication as observation data of real society [4-26]. However, the total number of the postings would not be enough for the estimation of the popularity of the entertainers and concerts. If an entertainers or concerts is really very excellent, the number of SNS posting does not decrease rapidly after a certain his/her event and their news. In addition there may be differences in the reaction depending on the type of SNS to use of people. But Many people will post their opinion for the event and they reply to the responses to other persons on SNS. Such active postings will be continuing in several days after the event and news. Thus, change of the day for each of the number of posting is important to estimate the popularity of concerts. In this paper, weshow that themathematical modelof thehitphenomenonisalso applicableto the predictionreputationofmusiciansin the(Englishspeaking) world, thebox officeof theconcert.We analyzed using the data of SNS (TOPSY PRO) the LADYGAGA has gained followers most Twitter in 2011. [27-37]. 
The International Journal of Multimedia \& Its Applications (IJMA) Vol.6, No.1, February 2014

\section{MATHEMATICAL THEORY FOR HIT PHENOMENA}

\subsection{Intention of each person for enjoying entertainment}

In this model, the communication with friends is considered as direct communication or two-body interaction. The rumor in societies is considered as indirect communication or three-body interaction. In this model, we define the intention for person " $i$ " in the society to entertainment activities as $I_{i}(t)$. the model can describe the intention of each person for enjoying entertainment as the equation of the intention of person $i$ with two-body interaction and three-body interaction terms. According to the Ref. 1, we write down the equation of the intention at the individual level as

$$
\frac{d I_{i}(t)}{d t}=-a I_{i}(t)+\sum_{j} d_{i j} I_{j}(t)+\sum_{j} \sum_{k} h_{i j k} d_{j k} I_{j}(t) I_{k}(t)+f_{i}(t)
$$

where $d_{i j}, h_{i j k}$, and $f_{i}(t)$ are the coefficient of the direct communication, the coefficient of the indirect communication, and the random effect for person $i$, respectively. We consider the above equation for every person in the society so that $i=1, \mathrm{~N}_{\mathrm{p}}$ where $N_{p}$ is the effective population of the society for a certain entertainment. The advertisement and publicity effect for each person can be described as the random effect $f_{i}(t)$.

Eq. (1) is the equation for all individual persons, but it is not convenient for analysis. Thus, we consider here the ensemble average of the intention of individual persons as follows:

$$
\langle I(t)\rangle=\frac{1}{N} \sum_{i} I_{i}(t)
$$

Taking the ensemble average of Eq. (1), we obtain for the left-hand side:

$$
\left\langle\frac{d I_{i}(t)}{d t}\right\rangle=\frac{1}{N} \sum_{i} \frac{d I_{i}(t)}{d t}=\frac{d}{d t}\left(\frac{1}{N} \sum_{i} I_{i}(t)\right)=\frac{d\langle I\rangle}{d t}
$$

For the right-hand side, the ensemble average of the first, second, and third is as follows:

$$
\begin{aligned}
& \left\langle-a I_{i}\right\rangle=-a \frac{1}{N} \sum_{i} I_{i}(t)=-a\langle I(t)\rangle \\
& \left\langle\sum_{j} d_{i j} I_{j}(t)\right\rangle=\left\langle\sum_{j} d I_{j}(t)\right\rangle=\frac{1}{N} \sum_{i} \sum_{j} d I_{j}(t)=\sum_{i} d \frac{1}{N} \sum_{j} I_{j}(t)=N d\langle I(t)\rangle
\end{aligned}
$$




$$
\begin{aligned}
\left\langle\sum_{j} \sum_{k} p_{i j k} I_{j}(t) I_{k}(t)\right\rangle & =\left\langle p \sum_{j} \sum_{k} I_{j}(t) I_{k}(t)\right\rangle \\
& =\frac{1}{N} \sum_{i} p \sum_{j} \sum_{k} I_{j}(t) I_{k}(t) \\
& =\sum_{i} p \frac{1}{N} \sum_{j} \sum_{k} I_{j}(t) I_{k}(t) \\
& =N p \sum_{i} \frac{1}{N} \sum_{j} I_{j}(t) \frac{1}{N} \sum_{k} I_{k}(t) \\
& =N^{2} p\langle I(t)\rangle^{2}
\end{aligned}
$$

where we assume that the coefficient of the direct and indirect communications can be approximated to beunder the ensemble average.

For the fourth term of Eq. (1), the random effect term, we consider that the random effect can be divided into two parts: the collective effect and the individual effect:

$$
\left\langle f_{i}(t)\right\rangle=\frac{1}{N} \sum_{i} f_{i}(t)=\langle f(t)\rangle
$$

where $\Delta f_{i}(t)$ means the deviation of the individual external effects from the collective effect, $\left\langle f_{i}(t)\right\rangle$. Thus, we consider here that the collective external effect term $\left\langle f_{i}(t)\right\rangle$ corresponds to advertisements and publicity to persons in the society. The deviation term $\Delta f_{i}(t)$ corresponds to the deviation effect from the collective advertisement and publicity effect for individual persons, which we can assume to be

$$
\left\langle\Delta f_{i}(t)\right\rangle=\frac{1}{N} \sum_{i} \Delta f_{i}(t)=0
$$

Therefore, we obtain the equation for the ensemble-averaged intention to entertainment in the following manner as shown in Ref.1:

$$
\frac{d\langle I(t)\rangle}{d t}=-a\langle I(t)\rangle+D\langle I(t)\rangle+P\langle I(t)\rangle^{2}+\langle f(t)\rangle
$$

Eq. (10) can be applied to the intention in the real entertainment market. For the calculations of box office movie in Ref.1, Eq. (10) should be solved in the way of Ref. 1 that the watched persons and unwatched persons are treated separately. For the examples of this paper, such effect can be neglected.In this paper, we have the media exposure of the daily value of the input. Therefore, we did not adapt this time the expression of decay, such as adapted to the hit phenomenon in the box office.

\subsection{Concerts and Advertisement}

We were with the advertising costs for input in mathematical models of the past.But this time, we adapted the following equation because you are media exposure of the daily input.Concerts and Advertisement are the very important factor to increase the intention of each person for enjoying entertainment. Concerts and Advertisement are done at Concerts Hall, LiveHouse, TV, newspaper and other media. We consider the advertisement effect as an external force term $\mathrm{A}(\mathrm{t})$ to the intention as follows, 
The International Journal of Multimedia \& Its Applications (IJMA) Vol.6, No.1, February 2014

$\frac{d I_{i}}{d t}=C_{a d v} A(t)+\sum_{j} D_{i j} I_{j}(t)+\sum_{j} \sum_{k} P_{i j k} I_{j}(t) I_{k}(t)$

where $D_{i j}$ is the factor for the direct communication and $P_{i j k}$ is the factor for the indirect communication. The factor Cadv corresponds to the strength of the impression of the media or Concerts exposure for each advertising campaign. Because of the term of the indirect communication, this equation is a nonlinear equation. If we consider Concerts and Advertisement, we can solve the equation by including several effect of the advertisement in the following way,

$C_{a d v} A(t) \Rightarrow \sum_{i} C_{i} A_{i}(t)$

where each coefficient $C_{i}$ corresponds to the each advertisement and Concert's counts and can be determined by using the random number technique introduced in Ref. [1]. The actual formula used in the calculation to analyse the SNS response are introduced in detail in Ref.[1].

\section{RESULTS}

\subsection{BOX OFFICE CONCERTS}

We found in Figure 1 that our calculation of the intention to entertainment for LADYGAGA shows very well agreement with the real observed WOM, where the paramaters in our calculation is adjusted using the Monte Carlo method to minimize the reliable factor R [2], the difference between the calculation curve and the observed WOM data. The result calculations are showed in Figure.1 for LADY GAGA. LADY GAGA is the very famous and popular female singer.To measure the LADY GAGA we choose May 2011, because the May 2011 measurement period was in theprocess of LADY GAGA is doing the tour. [27,28,29]And we thought worthy as the target period for measuring the topic of LADY GAGA the world because there was a chance of TV appearances LADYGAGA in many countries Asian countries, European countries, and America.In other words, We're easy to collect quantitatively the WOM data generated in the TV appearances andconcerts LADYGAGA around the world by choosing this time.In addition, in May 2011, the number of Twitter followers has become the world is LADYGAGA, the number wasmore than 11 million people. [35]From this point of view, LADYGAGA of May 2011 was a case suitable to analyze and predict the reputation around the world for artists.

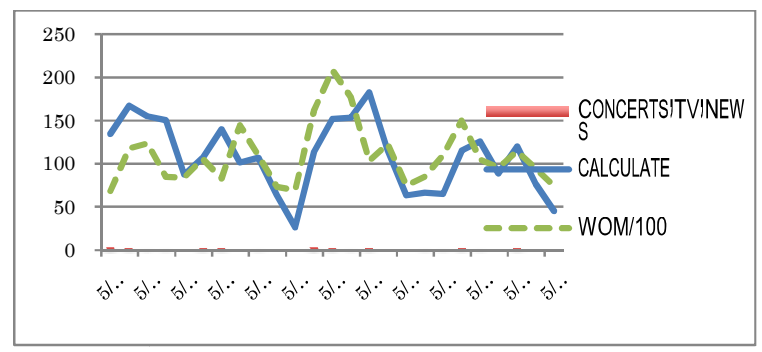

Figure 1.LADY GAGA Result of calculation (2011/5/5-2011/5/29) 
The International Journal of Multimedia \& Its Applications (IJMA) Vol.6, No.1, February 2014

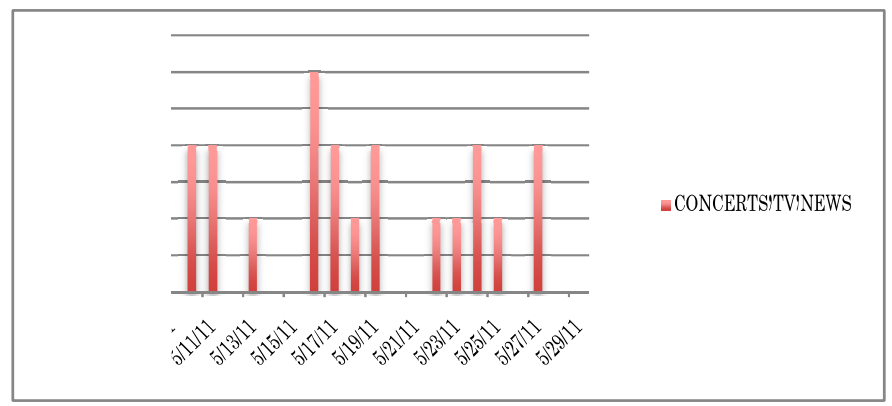

Figure 2.LADY GAGA Counts of Concerts and TV show.(2011/5/5-2011/5/29)

Table I.

Table of parameters for the LADYGAGA(2011/5/5-2011/5/29). Cadv is the strength of the advertisement; a is the decline factor of the advertisement; Dnn is the direct communication factor; Pnn is the indirect communication factor.

\begin{aligned} & alpha $=1.1324750155685943 \\ & \mathrm{Cadv}= 43.142879580057112 \\ &$ before $=7.4302797898577302 \\ & \mathrm{a}=0.62580002961937442 \\ & \mathrm{NpDnn}= 1.3620097995348740 \\ & \mathrm{~Np} 2 \mathrm{Pnn}=3.6883115111786188 \\ &$\hline\end{aligned}

Table II.

If the direct communication parameta's and indirect parameta's is zero a number.Table of parameters for the LADYGAGA(2011/5/5-2011/5/29). Cadv is the strength of the advertisement; a is the decline factor of the advertisement.
alpha $=7.6897501596183567$
$\mathrm{Cadv}=38.080751923437361$
before $=6.9111910247896300$
a $\quad=0.41499721499318115$

Value of Cadv have worked in the same way even if there is no indirect communication and direct communication. So We compare lowest WOM and highest WOM, and we analyzed how these simulation results has affected the value of Cadv.

Table III.

LADY GAGA WOM data/100 (2011/5/17-2011/5/29)

\begin{tabular}{|c|c|}
\hline date & WOM data/100 \\
\hline $2011 / 5 / 17$ & 208.52699 (Highest) \\
\hline $2011 / 5 / 18$ & 177.159 \\
\hline $2011 / 5 / 19$ & 103.28 \\
\hline $2011 / 5 / 20$ & 123.296 \\
\hline $2011 / 5 / 21$ & 74.749 \\
\hline $2011 / 5 / 22$ & 85.222 \\
\hline $2011 / 5 / 23$ & 110.007 \\
\hline $2011 / 5 / 24$ & 149.919 \\
\hline $2011 / 5 / 25$ & 105.165 \\
\hline $2011 / 5 / 26$ & 95.485 \\
\hline $2011 / 5 / 27$ & 114.629 \\
\hline $2011 / 5 / 28$ & 94.629 \\
\hline $2011 / 5 / 29$ & 74.07399999 (Lowest) \\
\hline
\end{tabular}


The International Journal of Multimedia \& Its Applications (IJMA) Vol.6, No.1, February 2014

Table IV.

Table of parameters for the LADYGAGA on 2011 May 29(Lowest).

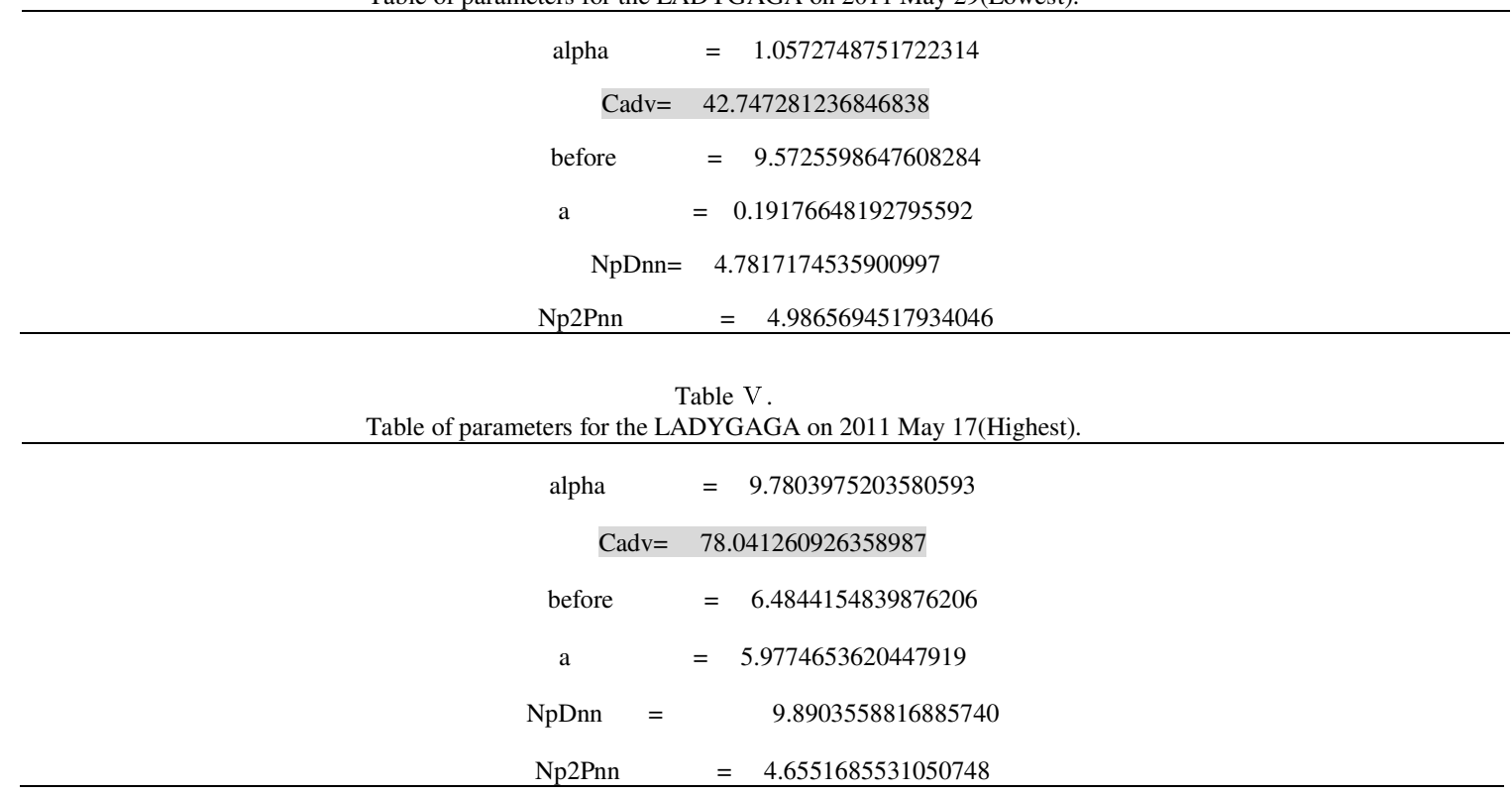

As we found in the figures and tabeles our calculations using Eq. (10) agree very well with the observed daily WOM data. Also from Table 4-5, Value of CadV was higher day rate of increase in the amount of high reviews. Value of Cadv was lower day rate of increase in the amount of low reviews.From these results, We also helped to validate accuracy of the parameters of this mathematical model. It is also possible that in raising the reputation of the artist, we consider the importance of increasing the Cadv. It can be expected to help make the application of mathematical models in the future.

In addition, as the results that are derived from Table 4-5, a fairly high value is in the parameters of the direct communication very high 5/29. It is not much different from the other day indirect communication. The reason, exposure on TV was high this time.We considered therefore, WOM by the viewer that said they were many. Therefore, we can consider that the mathematical model for hit phenomena using Eq. (10) can be applied also for the music entertainment. Therefore, our theory can be used to investigate human-human interaction especially those meant for entertainment. The main assumption underlying our theory is that the price of the target is not expensive enough that the consumer would not be affected by the advertisement. Thus, when producing music concerts, the concerts producer can use our theory to estimate the rough number of tickets sold and reputation of the musician from concerts, TV appearances and news[1-3,2736].

\section{CONCLUSiON}

We apply the mathematical theory for revenue prediction of Musician activity in the world using the mathematical Model of hit phenomena and The calculation using our mathematical model for hit phenomena presents the intention to entertainment in the society. Since the intention to entertainment in the society is considered to be proportional to the number of positing of blogs or Twitter, we can compare our calculation with observed number of daily posting of blog and Twitter. Evaluation of art and music is very important for art management and art marketing. 
The International Journal of Multimedia \& Its Applications (IJMA) Vol.6, No.1, February 2014

\section{ACKNOWLEDGEMENTS}

The authors would like to thank CEO Uchiyama Kouki of Hotlink, CEO Koguchi Hidehiko of Perspective Media, Theatre TinkerBell for giving them Database and helpful discussions. Great creaters who have supported the motivation of this study, We also thank versity KANSEI center for Arts and Science, ADAA (Asia Digital Arts Awards ) which gives the best environment to do their studies in particular, to carry out development activities creativity of Asia. In adidition, it is enormously grateful family and friends and Genda Lab. Members, also ancestors who have supported much emotional support. Y.Kawahata also thanks the Japan Student Services Organization for the scholarship.

\section{REFERENCES}

[1] A. Ishii, H. Arakaki, N. Matsuda, S. Umemura, T. Urushidani, N. Yamagata, and N. Yoshida, "The 'hit'phenomenon: a mathematical model of human dynamics interactions as a stochastic process," New Journal of Physics, vol. 14, pp. 063018, 2012.

[2] A Ishii, T Matsumoto and S Miki, "Revenue Prediction of a Local Event Using the Mathematical Model of Hit Phenomena, "Prog.Theor.Phys. :Suppli- ment,No.194 , pp.64-72, 2012.

[3] A Ishii, K Furuta, T Oka, H Koguchi and K Uchiyama, "Mathematical Model of Hit Phenomena as a theory for collective motion of human mind in societies, " the Frontiers of Artificial Intelligence and Applications (FAIA) series (IOS Press) in press.

[4] Kawahata, Y EtsuoGenda and Akira Ishii " Possibility of analysis of "Big Data" of Kabuki play in 19th century using the mathematical model of hit phenomena"ACE2013, unpublished.

[5] A Ishii, H Koguchi and K Uchiyama, "Mathematical Model of Hit Phenomena as a theory for human interaction in the society" the Lecture Notes of the Institute for Computer Sciences, Social Informatics and Telecommunications Engineering series volume 0126 (2013) p.159-164.

[6] Y Kawahata, E.Genda and A Ishii, ASIAGRAPH2013 in Kagoshima Proceedings, "Analysis of Stage Actors of Japan Using Mathematical Model of Hit Phenomena" in press.

[7] Y Kawahata, E.Genda and A Ishii, ASIAGRAPH2013 in Kagoshima Proceedings, "Analysis Reputation Prediction of Music Concerts Adopting the Mathematical Model of Hit Phenomena" in press

[8] Y Kawahata, E.Genda and A Ishii, ASIAGRAPH2013 in Kagoshima Proceedings, "Analysis of Facebook Adapting the Mathematical Model of Hit Phenomena" in press.

[9] Allsop DT, Bassett BR, and Hoskins JA, " Word-of-mouth research: principles and applications, "J. Advertising Research vol.47, pp.398, Dec 2007.

[10] Kostka J, Oswald Y A, and Wattenhofer R, Lecture Notes in Computer Science,2008, "Word of Mouth: Rumor Dissemination in Social Networks, "vol.5058, pp.185-196,2008.

[11] E. Bakshy, J. M. Hofman, W. A. Mason, and D. J. Watts, " Everyone's an Influencer: Quantifying Influence on Twitter, "In Fourth ACM International Conference on Web Seach and Data Mining (WSDM), Hong Kong, ACM, pp.65-74,2011.

[12] Jansen BJ, Zhang M, Sobel K, and Chowdury A, "Twitter power: Tweets as electronic word of mouth, "J. Am. Soc. Inform. Sci. Tech,vol.60,pp.2169-2188,Nov 2009.

[13] Brown, J. J., \&Reingen, P. H, "Social ties and word-of-mouth referral behavior, "Journal of Consumer Research,vol,14 (3), pp.350-362,1987.

[14] Murray, K.B, "A test of services marketing theory: consumer information acquisition activities, "Journal of Marketing 55, pp.10-25,Jan 1991.

[15] Banerjee A, Quarterly, "A Simple Model of Herd Behavior, "The Quarterly Journal of Economics ,vol.107 (3),pp.797-817,1992.

[16] Taylor J, "Word of Mouth Is Where It's At, "Brandweek, Brandweek,6/2/2003, vol. 44,Issue 22, pp.26,2003.

[17] Liu, Yong, "Word-of-Mouth for Movies: Its Dynamics and Impact on Box Office Revenue, "Journal of Marketing, vol.70 (3),pp.74-89,2006.

[18] Duan W, Gu B, and Whinston A B, "Do online reviews matter? An empirical investigation of panel data,"Decision Support Systems, vol.45,pp.1007-1016,2008.

[19] Duan W, Gu B and Whinston A B, "The dynamics of online word-of-mouth and product sales - an empirical investigation of the movie industry, "J. Retailing,vol.84, pp.233-242,2008. 
The International Journal of Multimedia \& Its Applications (IJMA) Vol.6, No.1, February 2014

[20] Pan R K and Sinha S, "The statistical laws of popularity: universal properties of the box-office dynamics of motion pictures, "New Journal of Physics,vol.12, pp.115004,2010.

[21] Asur S and Huberman R A, "Predicting the Future with Social Media, "Computers and Society (cs.CY); Physics and Society,pp.492-499,2010.

[22] Ratkiewicz J, Fortunato S, Flammini A, Menczer F, and Vespignani A, "Characterizing and Modeling the Dynamics of Online Popularity, "Phys.Rev.Lett.vol.105,pp. 158701-158704,2010.

[23] Eliashberg, J. Jonker, J. J. Sawhney, M. S. and Wierenga B, "MOVIEMOD: An Implementable DecisionSupport System for Prelaunch Evaluation of Motion Pictures, "Marketing Science, vol.19, pp.226-243,2000.

[24] F.M.Bass, "A New Product Growth Model for Consumer Durables," Management Science,vol.15,pp.215-227,1969.

[25] F.M.Bass, "The Adoption of a Marketing Model: Comments and Observations, "in Innovation Diffusion Models of New Product Acceptance, Mahajan V and Wind Y, eds., Ballinger, 1986.

[26] Dellarocas C, Awad NF, and Zhang X, "Strategic Manipulation of Internet Opinion Forums: Implications for Consumers and Firms, "2004 working paper, MIT Sloan School of Management,pp.38,2004.

[27] Dellarocas C, Zhang X, and Awad NF,J, "Exploring the value of online product reviews in forecasting sales, "The case of motion picturesInteractive Marketing,vol.21(4) ,pp.23-45,2007.

[28] "GagapediaTelevision appearances, "Retrieved.

[29] UNIVERSAL MUSIC "LADY GAGA NEWS, "2011-12-31 Retrieved.

[30] "Topsy", Available.at: http://topsy.com

[31] Samuel Bredl"How the US government is monitoring Social Media, "Digital Communications and Privacy,V200604,pp.36,2012.

[32] Bogers, T., \&Björneborn, L. "Micro-serendipity: Meaningful coincidences in everyday life shared on Twitter., "iConference 2013 Proceedings (2013).pp. 196-208. doi:10.9776/13175,2013.

[33] Thaiprayoon, S. Kongthon, A. ;Palingoon, P. ; Haruechaiyasak, C."Search result clustering for Thai Twitter based on Suffix Clustering,"ElectricalEngineering/Electronics,Computer,Telecommunications and Information Technology (ECTI-CON), 2012 9th International Conference on (May16-18 2012),pp.1-4,2012

[34] Adrian IrshadiSiregar, Budi PermadiIskandar"Measuring the Effectiveness of XL Axiata's Twitter Account in Handling Customers Complaints , "Journal of Business and Management,vol.1,5.

[35] STAN SCHROEDER "Lady Gaga Hits 10 Million Twitter Followers," Mashble,2011-05-17 Retrieved.

[36] "TourIntel",Available at; http://www.tourintel.com/terms.html 